\title{
Effects of a Neonatal Nursing Practice Program on Students' Stress, Self-efficacy, and Confidence
}

\author{
Yunsoo Kim ${ }^{1}$, Horan Park ${ }^{2}$, Sung Sil Hong ${ }^{3}$, Hee Jin Chung ${ }^{2}$ \\ ${ }^{1}$ Department of Nursing, Catholic Kwandong University, Gangneung; ${ }^{2}$ College of Nursing, The Catholic University of Korea, Seoul; \\ ${ }^{3}$ Department of Nursing, Kangwon National University, Samcheok, Korea
}

Purpose: The purpose of this study was to examine the effects of a neonatal nursing practice program for nursing students on students' stress, self-efficacy, and confidence. Methods: A 1-group pre- and post- study design was used. The participants consisted of 64 nursing students who were in a pediatric nursing clinical practicum at a nursing college in Seoul from September 2015 to May 2016. The program consisted of 3 stages-orientation, practice, and debriefing-and was conducted for 3 hours during a 2-week period of the pediatric nursing clinical practicum. The dependent variables were neonatal nursing practice stress, self-efficacy, and confidence. Data were analyzed using the paired t-test, the Pearson correlation coefficient, the $x^{2}$ test, and descriptive statistics with SPSS for Windows version 22.0. Results: The neonatal nursing practice program was effective at decreasing clinical practice-related stress and increasing confidence and self-efficacy regarding neonatal nursing practice. Conclusion: The neonatal nursing practice program may effectively promote the integration of theoretical knowledge and practice. In the future, we propose to develop various educational programs that reinforce basic nursing skills for neonates as part of an effective pediatric nursing clinical practicum.

Key words: Nursing student, Psychological stress, Self efficacy, Clinical competency, Practical nursing

\section{Corresponding author Ho Ran Park}

https://orcid.org/0000-0003-0867-1979

College of Nursing, The Catholic University of Korea,

222 Banpo-daero, Seocho-gu, Seoul 06591, Korea

TEL +82-2-2258-7406 FAX +82-2-2258-7772

E-MAIL hrpark@catholic.ac.kr

Received Jun 14, 2018 Revised Jun 25, 2018 Accepted Jun 25, 2018
(2) This is an Open Access article distributed under the terms of the Creative Commons Attribution NonCommercial License (http://creativecommons.org/licenses/by-nc/4.0/) which permits unrestricted noncommercial use, distribution, and reproduction in any medium, provided the original work is properly cited.

\section{INTRODUCTION}

The goal of nursing education is to produce nursing professionals who are competent in the skills required for health care domestically and internationally, which means that nursing education must cultivate in students' core faculties such as the integrated application of expertise and nursing skills, critical thinking, and leadership through theoretical education and clinical practice. It ultimately aims at producing graduates with hands-on nursing capabilities [1].

However, the medical environment is changing due to growing concerns about patients' safety and rights that have emerged due to recent cases of nosocomial infections, and now nursing students have very few opportunities to practice their nursing skills directly on patients during clinical practicums [2]. This is especially the case for pediatric nursing practicums, as the scope of students' practice is strictly limited due to factors such as the diverse ages of patients, parents' participation in nursing, and safety issues pertinent to pediatric patients. Furthermore, a trend exists in neonatal clinical practicums for more and more general and specialized hospitals to limit the scope of student practice during clinical rotations in light of the decrease in the birth rate and the increase in high- 
risk births, as well as concerns about infection [3]. As a result of all these changes, nursing students' clinical rotations are increasingly observation-based, rather than involving hands-on practice.

In order to alleviate these limitations of clinical practicums, simulations have been introduced and are being actively utilized [4]. In accordance with this trend, many domestic clinical nursing practice programs in pediatrics-especially in neonatal nursing-have developed and researched the efficacy of educational simulation programs designed to train students to treat newborn infants requiring intensive care [5-7]. Simultaneously, clinical rotations on normal infants still consist of traditional practicums, in which simple nursing tasks such as measuring vital signs, changing diapers, and feeding are orally explained. The only published study on a relevant educational program analyzed the effects of direct practice performing newborn health assessments [8], which means that research into educational programs that teach general basic nursing skills is currently nonexistent.

Nursing students experience considerable stress and tension when adapting to the unfamiliar, fast-changing hospital environment. The stress they undergo during practicums can reduce their interest in clinical rotations, decreasing the efficiency of their education and impairing their learning ability [9]. Nursing competency refers to nursing students' ability to perform on-site tasks on the basis of sufficient knowledge, technique, and attitudes; lower levels of nursing competency have been reported to lead to higher levels of stress [10].

Self-efficacy refers to the belief in one's own ability to successfully perform certain actions or activities, and it is the strongest factor in behavior change, as it determines one's performance of an action, one's level of effort, and one's level of resilience in the face of hardships [11]. Self-efficacy is important in education, as it not only improves competency itself, but also affects students' problem-solving skills and clinical judgment [12]. In general, people with higher self-efficacy can engage in tasks longer, approach problems more analytically, and view their chances of success more positively [11]. Self-efficacy is essential for nursing students to adapt effectively to the fast-changing medical environment [12].

Self-efficacy in nursing students is closely linked to their confidence in performing practical clinical tasks, which is among the main factors that determine the success of clinical practice. There is a large gap between knowledge of how to perform a task and actually performing it successfully. Based on the goals of nursing education, simulation-based education must ensure that students gain experience with the techniques, perceptions, and emotions that are essential components of actual clinical practice, and the criteria suggested for assessing the learning outcomes are knowledge, performance of nursing skills, students' satisfaction, critical thinking, and confidence in performance [13]. Therefore, it is necessary to grasp how clinical practice improves or diminishes nursing students' self-efficacy, and how it affects their confidence about performing neonatal nursing tasks, because doing so makes it possible to determine whether the goals of clinical practicums have been attained. Moreover, as mentioned above, lower levels of nursing competency lead to higher levels of stress; therefore, the correlation between changes in students' stress related to neonatal practice and changes in their confidence in performing nursing tasks must also be measured.

Based on the present condition of pediatric nursing practice education, this study focused on developing an educational program on nursing techniques; especially the clinical skills that nursing students use most often during neonatal practice, such as measuring the vital signs of newborn infants, performing intramuscular injections, and neonatal bathing. This paper also investigated the factors affecting students' stress regarding neonatal clinical practice, their confidence in clinical performance, and their self-efficacy, through which basic data for improving nursing students' pediatric clinical practice are provided.

\section{Objectives}

The purpose of this study was to measure the effects of a neonatal nursing practice program on students' stress, self-efficacy, and confidence, in order to establish basic data necessary for the development of an effective neonatal nursing practice curriculum. The specific goals were as follows:

- To conduct a pre-post comparison of nursing students' stress, self-efficacy, and confidence before and after the implementation of a neonatal nursing practice program.

- To conduct an analysis of changes in confidence in performing neonatal nursing tasks according to changes of stress and self-efficacy after a neonatal nursing practice program.

\section{METHODS}

\section{Research Design}

This study was designed to measure the effectiveness of a neonatal nursing practice program based on its effects on nursing students' stress, self-efficacy, and confidence. It was a pre-post comparative study of a single sample group.

\section{Research Subjects}

The subjects of this study were junior students at a nursing 
college in Seoul who completed the neonatal practice course between September 1, 2015 and May 31, 2016. Among the 79 nursing students who took the course, 8 students did so before the study started, and were therefore excluded. The remaining 71 nursing students stated that they understood the purpose and methodology of the study, and agreed to participate. The final data analysis included 64 of those students.

\section{Neonatal Nursing Practice Program}

\section{1) Development of the neonatal nursing practice program}

The neonatal nursing practice program was based on a previous version developed in 2011 at a nursing college in Seoul, and was edited and supplemented by the authors with a focus on the aspects of essential newborn care suggested by the World Health Organization [14], including thermal control of the newborn, umbilical cord care, and skin care. Additionally, clinical situations commonly experienced by nursing students during neonatal practice were emphasized. The developers included professors (the researchers of this paper) with $35+$ years of pediatric nursing education, nurses with 7+ years of neonatal experience, and a head neonatal nurse with approximately 20 years of clinical experience. They examined the validity of the content based on actual clinical nursing procedures, and the program was edited and supplemented to match the realistic expectations of the students. The program included neonatal practice goals, such as subject assessment, planning, intervention, and evaluation, all of which varied depending on the neonatal nursing process. The program itself comprised measuring a newborn's vital signs, performing an intramuscular injection of vitamin $\mathrm{K}$, and neonatal bathing before cord separation.

The evaluation form used to assess students' performance of the nursing tasks was structured with an emphasis on the core elements of the neonatal nursing process. The form was formatted as a checklist, and was organized in the order of measuring a newborn's vital signs, performing an intramuscular injection of vitamin $\mathrm{K}$, and neonatal bathing before cord separation. The evaluator responded to each question with 'performed' or 'did not perform.' The entire process of the neonatal nursing practice program and all evaluation items were developed by us, and the validity of the content was verified by neonatal nurses with $7+$ years of experience, as well as neonatal head nurses with 20 years of clinical experience.

\section{2) Implementation of the neonatal nursing practice program}

The neonatal nursing practice program was conducted in a clinical practice room at a nursing college in Seoul. The program consisted of 3 steps: orientation and case analysis ( $30 \mathrm{mi}-$ nutes); 20-minute group practice on nursing skills I and II (4 groups, 10 minutes per group); and debriefing (1 hour) (Figure $1)$. In the 16 weeks of the practice course, 2 weeks were allotted to clinical practice, in which the program was conducted once for each group. Each session comprised 3 hours of training for 8 groups.

The orientation was conducted for 30 minutes before the program, and it comprised 4 steps: grouping of students, an

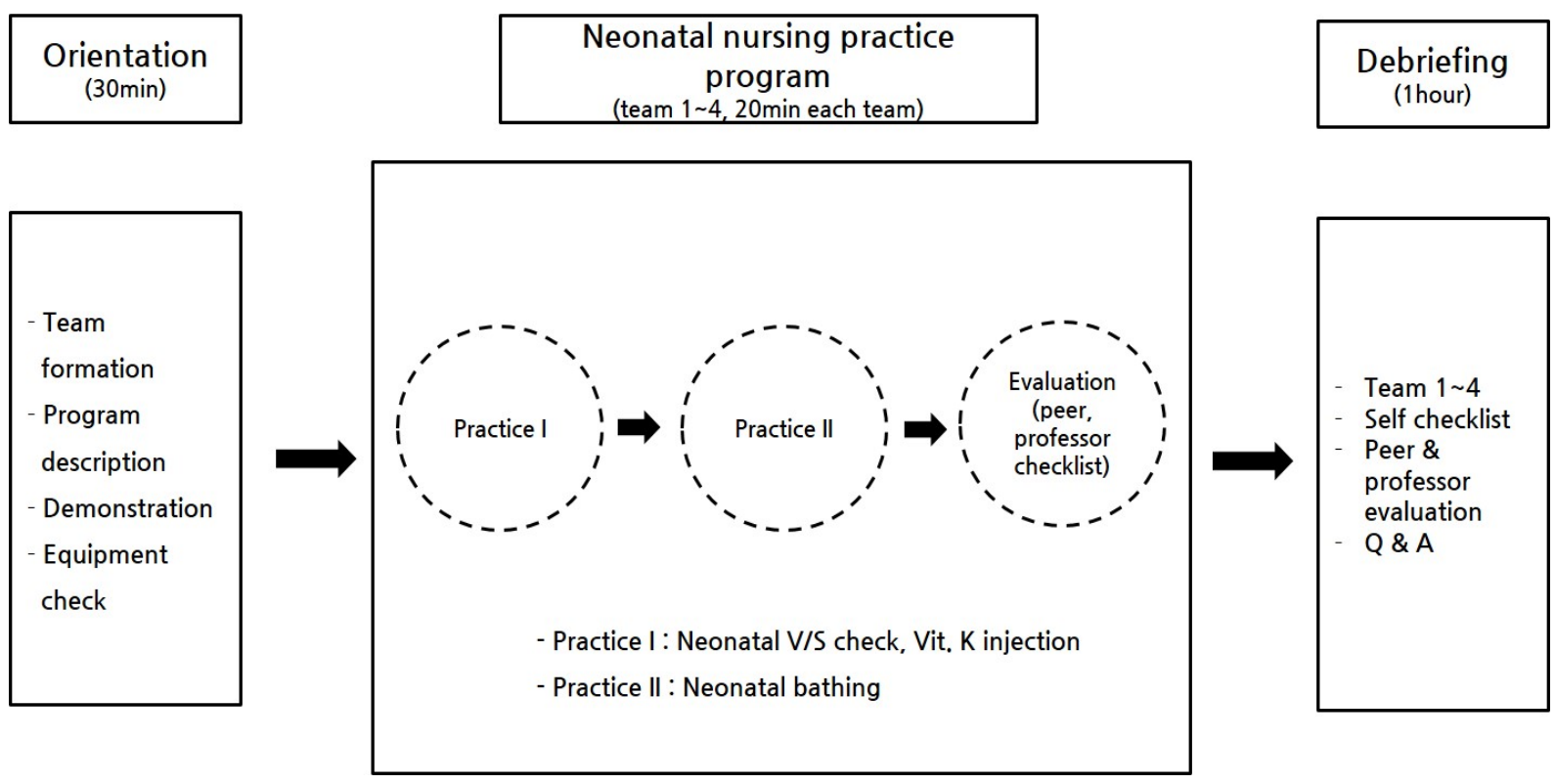

Figure 1. Framework of the program. 
introduction to the program, students' self-examination on items and apparatuses necessary for the neonatal nursing practice session, and a demonstration of the nursing skills. The students participated in the program in groups of 2 in the clinical practice room using a dummy infant. Each student took turns performing the planned nursing skills under the supervision of clinical faculty and a teaching assistant, and when a student was not actively performing a skill, he or she did a peer-review of the partner's skills to obtain further indirect experience of the pertinent nursing skills. The clinical faculty evaluated each student's performance using the checklist. After completing the program, students performed a selfevaluation, and the faculty and students collectively conducted a debriefing on the students' overall performance.

\section{Research Tool}

The study used a systematic questionnaire to collect data, and the use of tools other than those developed by the authors received prior approval from the developers.

\section{1) Neonatal nursing practice stress}

The practice-related stress that nursing students experienced in the neonatal unit was measured by a visual analogue scale (VAS), on which 10 was the highest score. The neonatal practice stress tool was co-developed by 2 researchers based on the general stress experienced during neonatal practicums and the stress specifically related to the 6 nursing skills most commonly used in neonatal nursing practice. The validity of the content was confirmed by nurses with 20 years of neonatal experience. The items included in the stress tool were: measuring a newborn's body temperature, measuring a newborn's heart rate, respiratory rate, neonatal warming, neonatal bathing, and performing intramuscular injections. Students were asked to mark their level of stress on a horizontal line of 10 centimeters, on which 0 equated to "no stress" and 10 equated to "very severe stress". Each mark was measured with a ruler and converted into a score, with higher scores indicating higher levels of stress experienced by the students.

\section{2) Self-efficacy}

Nursing students' self-efficacy before and after the neonatal nursing practice program was measured in 3 categories: general self-efficacy, academic self-efficacy, and social self-efficacy.

General self-efficacy refers to the belief in one's own ability to successfully perform specific assignments or activities, or one's belief in his/her own competency in diverse situations [15]. This study used the general self-efficacy instrument developed by Kim [16], which consisted of 24 questions, includ- ing 7 questions on self-confidence, 12 questions on self-control efficacy, and 5 questions on the preferred difficulty level of assignments. The instrument used a 6-point Likert scale.

Academic self-efficacy is a motivational variable by which a learner's level of academic performance and achievement in general learning situations can be predicted; in this study, academic self-efficacy was developed using the instrument developed by Kim and Park [17]. The instrument consisted of 28 questions, including 10 questions on the preferred difficulty level of assignments, 10 questions on self-control efficacy, and 8 questions on self-confidence. The instrument used a 6-point Likert scale.

Social self-efficacy refers to one's belief in his/her ability to deliver a proper impression of oneself by utilizing appropriate skills in social situations [18]. This can be an indicator of possible academic achievement and social adaptability, as well as an index by which an individual's social behavior can be understood and explained. This study used the instrument developed to measure social self-efficacy by Kang and Kim [19], which consisted of 8 questions: 2 questions on relationship formation and maintenance, 2 questions on expressing opinions, 2 questions on knowledge of patients' rights, and 2 questions on requesting help. The instrument used a 6-point Likert scale.

A higher score on each instrument signified higher general, academic, and social self-efficacy, respectively. In terms of reliability, each instrument-general self-efficacy, academic selfefficacy, and social self-efficacy-was reported to have a Cronbach's $\alpha>.80$ at the time of development $[16,17,19]$, and the reliability of each instrument in this study was confirmed, with Cronbach's $\alpha$ values of .88 for general self-efficacy, .86 for academic self-efficacy, and .83 for social self-efficacy.

\section{3) Neonatal nursing practice confidence}

Nursing students' confidence in neonatal nursing practice was measured by a neonatal nursing practice confidence tool developed by the authors. The contents of the instrument were co-developed by 2 of the researchers based on the educational content for students in the neonatal nursing practice program, and its validity was confirmed by nurses with 20 years of neonatal experience. The tool consisted of 12 questions: 1 question on approaching the patient, 3 questions on measuring a newborn's vital signs, 4 questions on administering a vitamin K injection to newborns, and 4 questions on neonatal bathing. Confidence in neonatal nursing practice was measured on a 4-point Likert scale, in which 1 equated to "I can't do it." and 4 equated to "I am confident I can do it.". A higher score indicated higher neonatal nursing confidence, and the reliability of the instrument was high, with a Cronbach's $\alpha$ of .88 . 


\section{4) General characteristics}

The general characteristics consisted of 2 items: students' satisfaction with their major, and their satisfaction/stress with clinical practicums in general; these items were confirmed to be the primary factors that affected students' practice stress and satisfaction by the study of Park and Jang [20]. These 2 factors were checked by 1 question each. For the questions asking whether they were satisfied with their major and clinical practice, a score of 5 equated to "I am very satisfied.", while a score of 1 equated to "Not at all.". The survey used a 5-point Likert scale, and the measurement of general clinical practice stress used a VAS on which 10 was the highest score. A higher score indicated higher satisfaction with the major and higher satisfaction or higher stress with clinical practice in general.

\section{Data Collection}

The data collection for this study was conducted from October 10, 2015 to May 31, 2016, and it was initiated after receiving approval from the Institutional Review Board (No. NC15Q1SI0107). The purpose and intent of the study were explained to the participating students by the researchers themselves, and the survey was done after the research consent form was signed by the students. It was also explained that non-participants would not face any disadvantages.

The survey before the neonatal nursing practice program was done on a Friday afternoon during the pediatric practice orientation, in the week before the practicum week, and the post-survey was done following the practicum evaluation meeting, after 2 weeks of practice.

The survey required 15 minutes on average, and all participants' responses were anonymous to ensure the students' voluntary participation. A total of 71 questionnaires were submitted, but 7 were excluded because they were incomplete; thus, a total of 64 questionnaires were included in the final analysis.

\section{Data Analysis}

The collected data were analyzed with SPSS version 21.0. A descriptive statistical analysis of the frequency, mean value, and standard deviation was conducted to characterize the participants' general characteristics, and the paired t-test was utilized to analyze differences in stress, self-efficacy, and confidence before and after the program. Correlations between variables were analyzed using the Pearson correlation coefficient, and causal relationships between stress, self-efficacy, and confidence were analyzed using the $x^{2}$ test.

\section{RESULTS}

\section{General Characteristics of Subjects}

The average age of the subjects was 22.17 years, and males comprised $12.5 \%$ of the total subjects, while females accounted for the remaining $87.5 \%$. The average score for their satisfaction with their major was 3.77 , the average score for their satisfaction with clinical practicums was 3.67 , and the average score for stress from practice in general was 7.21 (Table 1).

Table 1. General Characteristics of Students

$(N=64)$

\begin{tabular}{lcc}
\hline Characteristics & $\mathrm{n}(\%)$ or $\mathrm{M} \pm \mathrm{SD}$ \\
\hline Age (year) & & $22.17 \pm 2.25$ \\
Gender & Male & $8(12.5)$ \\
& Female & $56(87.5)$ \\
Satisfaction with major & $3.77 \pm 0.73$ \\
Satisfaction with clinical practice & $3.67 \pm 0.82$ \\
Clinical practice-related stress & $7.21 \pm 1.78$ \\
\hline
\end{tabular}

\section{Differences in Stress, Self-efficacy, and Confidence before and after the Neonatal Nursing Practice Program}

The differences in stress, self-efficacy, and confidence before and after the neonatal nursing practice program are presented in Table 2.

Neonatal practice-related stress declined in every area except stress from practice in general, and every decrease proved to be statistically significant. The skills that showed the largest decrease were measuring the pulse $(\mathrm{t}=3.37, p=.001)$, intramuscular injections $(\mathrm{t}=3.10, p=.003)$, and measuring the body temperature $(\mathrm{t}=3.47, p=.001)$. Intramuscular injections and neonatal bathing showed the highest levels of stress before the program (5.97 and 5.69 respectively), but those scores dropped to 4.77 and 4.88 , reflecting lower than moderate levels, after the program.

Self-efficacy showed a statistically significant increase after the neonatal practice program in all 3 areas: general self-efficacy ( $\mathrm{t}=3.84, p<.001)$; academic self-efficacy $(\mathrm{t}=2.18, p=.033)$; and social self-efficacy $(\mathrm{t}=3.52, p=.001)$.

Lastly, in the survey on neonatal nursing practice confidence, which was on a 5-point scale, the general score showed a statistically significant increase from 2.56 before the program to 3.31 after the program $(\mathrm{t}=11.43, p<.001)$. More specifically, answers to "I can name 6 rights for medication safety." showed the highest score of 3.42, and answers to "I can put on diapers and clothes after bathing a newborn." showed the sec- 
ond highest score of 3.41. The items that showed the largest score increase were "I can perform newborn umbilical cord management.", and "I can give newborns an intramuscular injection in the correct way.".

\section{Correlations between Stress, Self-efficacy, and Confidence}

The correlations between the outcome variables are presented in Table 3. Neonatal practice-related stress showed a significant negative correlation with general self-efficacy $(\mathrm{r}=$

Table 2. Differences in Stress, Self-efficacy, and Confidence after the Neonatal Nursing Practice Program

$(N=64)$

\begin{tabular}{|c|c|c|c|c|c|}
\hline \multirow{2}{*}{ Characteristics } & Pre & Post & \multirow{2}{*}{ Difference } & \multirow{2}{*}{$\mathrm{t}$} & \multirow{2}{*}{$p$} \\
\hline & $\mathrm{M} \pm \mathrm{SD}$ & $\mathrm{M} \pm \mathrm{SD}$ & & & \\
\hline \multicolumn{6}{|l|}{ Neonatal nursing practice stress } \\
\hline Total stress & $6.14 \pm 2.02$ & $6.29 \pm 2.23$ & $0.14 \pm 2.85$ & 0.40 & .692 \\
\hline Body temperature measurement & $4.19 \pm 2.20$ & $2.98 \pm 1.98$ & $-1.20 \pm 2.77$ & 3.47 & .001 \\
\hline Pulse measurement & $4.59 \pm 2.40$ & $3.38 \pm 1.95$ & $-1.22 \pm 2.90$ & 3.37 & .001 \\
\hline Breath measurement & $4.55 \pm 2.43$ & $3.59 \pm 2.06$ & $-0.95 \pm 3.07$ & 2.49 & .016 \\
\hline Neonatal warming & $4.56 \pm 2.29$ & $3.61 \pm 2.11$ & $-0.95 \pm 2.78$ & 2.74 & .008 \\
\hline Neonatal bathing & $5.69 \pm 2.80$ & $4.88 \pm 2.37$ & $-0.81 \pm 2.99$ & 2.17 & .034 \\
\hline Intramuscular injection & $5.97 \pm 2.78$ & $4.77 \pm 2.59$ & $-1.20 \pm 3.11$ & 3.10 & .003 \\
\hline \multicolumn{6}{|l|}{ Self-efficacy } \\
\hline General self-efficacy & $3.75 \pm 0.52$ & $4.01 \pm 0.50$ & $0.26 \pm 0.55$ & 3.84 & $<.001$ \\
\hline Academic self-efficacy & $3.66 \pm 0.51$ & $3.79 \pm 0.59$ & $0.13 \pm 0.46$ & 2.18 & .033 \\
\hline Social self-efficacy & $3.87 \pm 0.67$ & $4.16 \pm 0.74$ & $0.29 \pm 0.66$ & 3.52 & .001 \\
\hline Neonatal nursing practice confidence & $2.56 \pm 0.41$ & $3.31 \pm 0.37$ & $0.75 \pm 0.52$ & 11.43 & $<.001$ \\
\hline I can handle real newborn babies. & $2.30 \pm 0.63$ & $3.17 \pm 0.38$ & $0.88 \pm 0.66$ & 10.69 & $<.001$ \\
\hline I can measure the tympanic temperature of a newborn baby. & $2.84 \pm 0.44$ & $3.31 \pm 0.50$ & $0.47 \pm 0.59$ & 6.36 & $<.001$ \\
\hline I can measure the pulse of a newborn baby. & $2.83 \pm 0.52$ & $3.27 \pm 0.48$ & $0.44 \pm 0.66$ & 5.27 & $<.001$ \\
\hline I can measure the respiration of a newborn baby. & $2.84 \pm 0.51$ & $3.27 \pm 0.45$ & $0.42 \pm 0.64$ & 5.29 & $<.001$ \\
\hline I can name 6 rights for medication safety. & $3.14 \pm 0.53$ & $3.42 \pm 0.56$ & $0.28 \pm 0.77$ & 2.94 & .005 \\
\hline I can prepare the exact dose of vitamin $K$ to be injected into a newborn. & $2.63 \pm 0.72$ & $3.33 \pm 0.51$ & $0.70 \pm 0.89$ & 6.36 & $<.001$ \\
\hline I can select an intramuscular injection site for a newborn baby. & $2.42 \pm 0.69$ & $3.39 \pm 0.49$ & $0.97 \pm 0.82$ & 9.50 & $<.001$ \\
\hline I can give newborns an intramuscular injection in the correct way. & $2.33 \pm 0.74$ & $3.34 \pm 0.51$ & $1.02 \pm 0.81$ & 10.07 & $<.001$ \\
\hline I can prepare the necessary supplies for bathing a newborn. & $2.34 \pm 0.65$ & $3.31 \pm 0.47$ & $0.97 \pm 0.78$ & 9.99 & $<.001$ \\
\hline I can bathe a newborn baby. & $2.25 \pm 0.62$ & $3.22 \pm 0.42$ & $0.97 \pm 0.69$ & 11.24 & $<.001$ \\
\hline I can perform newborn umbilical cord management. & $2.23 \pm 0.68$ & $3.30 \pm 0.46$ & $1.06 \pm 0.81$ & 10.44 & $<.001$ \\
\hline I can put on diapers and clothes after bathing a newborn. & $2.59 \pm 0.66$ & $3.41 \pm 0.50$ & $0.81 \pm 0.85$ & 7.63 & $<.001$ \\
\hline
\end{tabular}

Table 3. Relationships between Neonatal Practice-related Stress, Confidence, and Self-efficacy

$(N=64)$

\begin{tabular}{|c|c|c|c|c|c|}
\hline Variables & $\begin{array}{c}\text { Neonatal } \\
\text { practice-related } \\
\text { stress }\end{array}$ & $\begin{array}{l}\text { General } \\
\text { self-efficacy }\end{array}$ & $\begin{array}{l}\text { Academic } \\
\text { self-efficacy }\end{array}$ & $\begin{array}{c}\text { Social } \\
\text { self-efficacy }\end{array}$ & $\begin{array}{c}\text { Confidence in } \\
\text { neonatal nursing } \\
\text { practice }\end{array}$ \\
\hline & $\mathrm{r}(p)$ & $\mathrm{r}(p)$ & $\mathrm{r}(p)$ & $\mathrm{r}(p)$ & $\mathrm{r}(p)$ \\
\hline $\begin{array}{l}\text { Neonatal nursing } \\
\text { practice stress }\end{array}$ & 1 & & & & \\
\hline $\begin{array}{l}\text { General } \\
\text { self-efficacy }\end{array}$ & $\begin{array}{c}-.26 \\
(.039)\end{array}$ & 1 & & & \\
\hline $\begin{array}{l}\text { Academic } \\
\text { self-efficacy }\end{array}$ & $\begin{array}{c}-.13 \\
(.307)\end{array}$ & $\begin{array}{c}.61 \\
(<.001)\end{array}$ & 1 & & \\
\hline $\begin{array}{l}\text { Social } \\
\text { self-efficacy }\end{array}$ & $\begin{array}{c}-.02 \\
(.859)\end{array}$ & $\begin{array}{c}.51 \\
(<.001)\end{array}$ & $\begin{array}{c}.51 \\
(<.001)\end{array}$ & 1 & \\
\hline $\begin{array}{l}\text { Confidence in neonatal } \\
\text { nursing practice }\end{array}$ & $\begin{array}{c}-.16 \\
(.193)\end{array}$ & $\begin{array}{c}.41 \\
(.001)\end{array}$ & $\begin{array}{c}.19 \\
(.124)\end{array}$ & $\begin{array}{c}.25 \\
(.043)\end{array}$ & 1 \\
\hline
\end{tabular}


-.26, $p=.039)$, while a positive correlation was observed between general self-efficacy and academic self-efficacy $(\mathrm{r}=.61$, $p<.001)$, as well as between social self-efficacy $(\mathrm{r}=.51, p<.001)$ and academic self-efficacy. Confidence in neonatal nursing practice showed a significant positive correlation with general self-efficacy $(\mathrm{r}=.41, p=.001)$, as well as with social self-efficacy $(\mathrm{r}=.25, p<.043)$.

\section{Changes in Confidence according to Changes in Stress and Self-efficacy after the Neonatal Nursing Practice Program}

Changes in confidence in neonatal nursing practice according to changes in stress and self-efficacy after the neonatal nursing practice program are presented in Figure 2.

Neonatal practice-related stress increased in 13 participants $(20.3 \%)$, was unchanged in $12(18.8 \%)$, and decreased in 39 $(60.9 \%)$. After the neonatal nursing practice program, the percentage of participants who reported an increase in confidence was $84.6 \%$ among those who reported increased stress, $92.9 \%$ in those who reported unchanged stress, and $91.7 \%$ in those who reported decreased stress. The average was $89.1 \%$.

After the neonatal nursing practice program, general selfefficacy increased in 40 participants $(62.5 \%)$, was unchanged in $3(4.7 \%)$, and decreased in $2(32.8 \%)$. Academic self-efficacy increased in 41 participants $(64.1 \%)$, was unchanged in $2(3.1 \%)$, and decreased in 21 (32.8\%). Social self-efficacy increased in
39 participants $(60.9 \%)$, was unchanged in $7(11.0 \%)$, and decreased in 18 (28.1\%).

After the neonatal nursing practice program, the percentage of participants who reported an increase in confidence was $93 \%$ among those who experienced increased general selfefficacy, $100 \%$ among those whose general self-efficacy was unchanged, and $81 \%$ among those whose general self-efficacy decreased; the average was $89.1 \%$. Increased confidence was reported by $92.7 \%, 50.0 \%$, and $85.1 \%$ of participants whose academic self-efficacy increased, was unchanged, or decreased, respectively; the average was $89.1 \%$. The corresponding proportions were $92.1 \%, 100.0 \%$, and $77.8 \%$ for those who experienced increased, unchanged, or decreased social self-efficacy, respectively; the average was $89.1 \%$.

\section{DISCUSSION}

The purpose of this study was to obtain basic data that could be used to improve nursing students' neonatal experiences of clinical practicums through examining the effects of a neonatal nursing practice program on students' stress, self-efficacy, and confidence in neonatal nursing practice. In order to help students with neonatal practicums, which they found difficult, the program created quasi-neonatal situations with the intention of alleviating students' neonatal nursing-related stress and improving their self-efficacy and confidence.

The pre- and post-program variables used to measure the
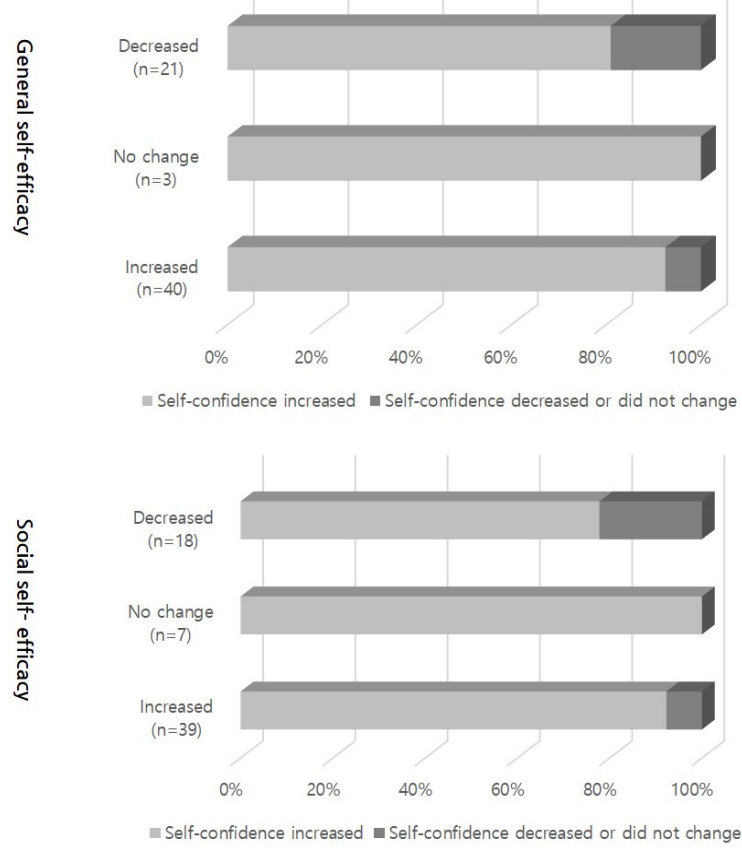

Figure 2. Changes in confidence in neonatal nursing practice according to changes in stress and self-efficacy after the neonatal nursing practice program. 
effects of the neonatal nursing practice program in this study were chosen based on the learning outcomes of simulation education suggested by Jeffries [13]. These variables- stress, confidence in neonatal nursing practice, and self-efficacy-were repeatedly measured.

Due to the lack of previous studies that used subjects, programs, and measurement tools identical to those used in this study, a direct comparison with previous studies could not be made. Therefore, the discussion will focus on prior studies in which pediatric nursing students were studied using similar instruments.

First, neonatal practice-related stress in this study declined in all areas, except for practice-related stress in general. The areas with the highest stress levels were intramuscular injections and neonatal bathing, which matches the results of a previous study [7], in which nursing students identified infection prevention and bathing as the most difficult subjects in neonatal care. This means that intramuscular injection and newborn bathing need to be included in new neonatal nursing practice programs in the future.

The results of this study indicate that nursing students' stress regarding neonatal practice in general was moderate, and it did not decrease after the neonatal nursing practice program. On a 10-point scale, neonatal practice-related stress was 6.14 before the program and 6.29 after the program, which is similar to the score of 3.33 out of 5 reported by Kim and Lee [21] and the score of 3.56 out of 5 reported by Whang [22]. Although direct comparisons cannot be made due to differences in criteria, the level of the clinical facility, and research subjects' characteristics, all these studies indicate that students experience a moderate level of stress during clinical practicums. The current state of neonatal clinical practicums for nursing students in Korea limits their role to safe and simple tasks such as diaper changing and feeding, due to safety concerns about newborns. In fact, students are hardly allowed to perform even these simple tasks; instead, they mostly observe. Therefore, efforts need to be made to implement a neonatal nursing practice program before actual clinical practicums, in order to reduce nursing students' stress related to clinical practice.

In this study, we found that the neonatal nursing practice program was also effective for improving students' self-efficacy, as general self-efficacy, academic self-efficacy, and social self-efficacy all improved after the program. Self-efficacy is formed by actual or indirect experiences, praise, and encouragement, and is influenced by observing the success of someone similar to oneself [23]. In this study, students' self-efficacy was formed by the experience of performing neonatal physical assessments and basic nursing skills on dummy infants, and it was improved by getting compliments on what they did well during the debriefing, as well as by observing the successful practice of other students if the students had any elements that were lacking. These positive outcomes seem to have been the result of a realistic practice program that used infant dummies, which enhanced the verisimilitude of the setting, thereby boosting students' attitude and will to learn. We found that neonatal practice-related stress only had a significant negative correlation with general self-efficacy, which does not agree with Whang's study [22], in which clinical practice-related stress did not show a meaningful correlation with self-efficacy. Students' stress in the clinical practice environment largely arises from their lack of expertise and techniques, which causes severe tension and stress that hinder the students' efficiency in clinical practicums [22]. There are several differences between clinical practicums for adult patients and for neonates, including the fact that parental agreement is required for hands-on neonatal practice and the increasing concerns about neonatal infections; all these elements seem to affect students' tension and stress, ultimately hindering their self-efficacy.

Confidence in neonatal nursing practice was reported to be lower than moderate for all skills before the program, but the post-program survey showed improvements for all skills. The specific skills where below-average confidence was reported before the program were: "I can handle real newborn babies.", "I can bathe a newborn baby.", "I can perform newborn umbilical cord management.", and "I can give newborns an intramuscular injection in the correct way.", indicating students' low levels of confidence in direct neonatal nursing in general. However, these areas showed major increases in confidence after the program, confirming the effect of the neonatal nursing practice program. Lower levels of confidence were also reported for skills related to newborn bathing (e.g. neonatal bathing, supply preparation, and umbilical cord management) and neonatal intramuscular injections before the program, and these skills showed higher levels of neonatal practice-related stress as well. This suggests a correlation between students' stress regarding these skills and their confidence in practice. Therefore, education on neonatal nursing practice in the future will need to reinforce the items related to intramuscular injections and neonatal bathing. This result corresponds with those of 2 major previous studies [8,24]. This correlation can be explained through the fact that students could directly put their knowledge into action after the nursing practice program at actual clinical sites during their neonatal practicums. It seems that neonatal nursing practice programs will need to be implemented before actual neonatal practicums in the future.

Confidence in neonatal nursing practice proved to be positively correlated with general self-efficacy and social self-effi- 
cacy. This agrees with the results of a previous study [25], in which nursing students' self-efficacy was linked to their clinical practice confidence and was found to be a major factor that determined the success of their clinical practicums.

In this study, the rate of participants who reported an increase in neonatal nursing confidence was $89 \%$, regardless of the change in their self-efficacy after completing the neonatal nursing practice program, which indicates that students' confidence generally increased. Although a direct comparison cannot be made due to the lack of previous studies in which nursing practice-related confidence and self-efficacy were analyzed, these results correspond to those of previous studies [26,27], in which higher self-efficacy increased confidence in practice. This study used hands-on practice with dummy infants to help students perform successfully on specific assignments and activities, while also providing them with skills necessary for social situations. Furthermore, by evaluating the students' performance via a checklist, each learner's level of academic achievement could be estimated, which led to an increase in students' confidence. In the future, an educational program needs to be developed in which both self-efficacy and neonatal nursing practice confidence can be improved.

The goal of pediatric practice in neonatal nursing education is to help students grasp a newborn's health problems based on a proper physical assessment, and to improve their nursing competency for each nursing process. Therefore, a strategy must be sought through which a direct practice program could be promoted; such a program could contribute to the positive experiences of nursing students at clinical sites.

The discussion thus far has confirmed that the neonatal nursing practice program had positive impacts on nursing students' self-efficacy and neonatal nursing competency, implying that such a program could be a valuable learning method in which theoretical knowledge and actual field work would be efficiently integrated. Therefore, the results of this study are expected to provide directions for efficient education in pediatric nursing practice, and we suggest that an educational program should be developed in which basic neonatal nursing skills such as intramuscular injections and neonatal bathing are reinforced. However, this study is limited in that its study subjects were students from a single nursing college, which means that it was an intervention study on a single group. In future studies, a wider range of participants and a comparison group will be required to verify the program's validity in greater depth.

\section{CONCLUSION}

The purpose of this study was to examine how a neonatal nursing practice program influenced nursing students' neo- natal nursing practice-related stress, self-efficacy, and confidence.

The neonatal nursing practice program decreased nursing students' practice-related stress, while increasing their self-efficacy and confidence. It was confirmed that the neonatal nursing practice program effectively complemented the actual neonatal practicum, which barely allows students to obtain hands-on practice in the current clinical environment, and that it was helpful for the improvement of students' selfefficacy. This study is significant in that it could serve as a reference point for effective pediatric practice education and improvements in students' self-efficacy in the future.

\section{Conflict of interest}

No potential or any existing conflict of interest relevant to this article was reported.

\section{REFERENCES}

1. KABoN. Nurses' core competencies and nursing education learning outcomes 2012 [Internet]. Seoul: KABoN; 2012 [cited 2018 June 15]. Available from:

http://www.kabone.or.kr/HyAdmin/upload/goodFile/1201211 27132143.pdf.

2. Song KA, Park HJ, Yeom HA, Lee JE, Joo GE, Kim HJ. The development and evaluation of a new educational program, introduction to clinical nursing, for third year nursing students. Journal of Korean Academy of Fundamentals of Nursing. 2012;19(3):322-333. https://doi.org/10.7739/jkafn.2012.19.3.322

3. Yoo SY, Kim SH, Lee JH. Educational needs in the development of a simulation based program on neonatal emergency care for nursing students. Journal of Korean Academy of Child Health Nursing. 2012;18(4):170-176. https://doi.org/10.4094/jkachn.2012.18.4.170

4. Parker RA, McNeill JA, Pelayo LW, Goei KA, Howard J, Gunter MD. Pediatric clinical simulation: A pilot project. Journal of Nursing Education. 2011;50(2):105-111.

https://doi.org/10.3928/01484834-20101230-05

5. Kim SG. Effects of a simulation-based high-risk neonatal care education on learning satisfaction, class participation, learning motivation and clinical competency in nursing students. Journal of the Korea Academia-Industrial cooperation Society. 2015;16(10): 6807-6815. https://doi.org/10.5762/KAIS.2015.16.10.6807

6. Park SN, Kim YS. Stress and satisfaction from simulation-based practice and clinical practice on high-risk newborn nursing. The Journal of Korean Academic Society of Nursing Education. 2015; 21(1):86-94.

7. Park S, Ji ES. Clinical competence according to experiences on the neonatal nursing care in nursing students and educational needs 
of the nursing simulation. The Journal of Learner-Centered Curriculum and Instruction. 2016;16(7):97-112.

8. Park SH, Ryu SA. Effects of direct practice of newborn health assessment on students' nursing clinical competence and self-efficacy. Child Health Nursing Research. 2016;22(2):117-125.

https://doi.org/10.4094/chnr.2016.22.2.117

9. Choi GY. The relationship between perceptions of nursing college students regarding clinical practice environment and related variables. Korean Journal of Adult Nursing. 2009;21(1):129-139.

10. Lee AK, You HS, Park IH. Affecting factors on stress of clinical practice in nursing students. Journal of Korean Academy of Nursing Administration. 2015;21(2):154-163. https://doi.org/10.11111/jkana.2015.21.2.154

11. Bandura A. Self-efficacy: Toward a unifying theory of behavioral change. Psychological Review. 1977;84(2):191-215. https://doi.org/10.1037/0033-295X.84.2.191

12. Kendall S, Bloomfield L. Developing and validating a tool to measure parenting self-efficacy. Journal of Advanced Nursing. 2005; 51(2):174-181. https://doi.org/10.1111/j.1365-2648.2005.03479.x

13. Jeffries PR. A framework for designing, implementing, and evaluating: Simulations used as teaching strategies in nursing. Nursing Education Perspectives. 2005;26(2):96-103.

14. World Health Organization. WHO recommendations on postnatal care of the mother and newborn [Internet]. Geneva: World Health Oganizaion; 2014 [cited 2018 June 15]. Available from: http://apps.who.int/iris/bitstream/handle/10665/97603/97892 41506649_eng.pdf;jsessionid=525343D1B10251B4B031381D3C6B4 235 ? sequence $=1$.

15. Judge TA, Locke EA, Durham CC, Kluger AN. Dispositional effects on job and life satisfaction: The role of core evaluations. The Journal of Applied Psychology. 1998;83(1):17-34.

16. Kim AY. A study on the academic failure - tolerance and its correlates. Journal of Educational Psychology. 1997;11(2):1-19.

17. Kim AY, Park IY. Study on the construct of academic self-efficacy and its measurement. The Journal of Educational Research. 2001; 39(1):95-123.
18. Kwon EM, Shin MS, Kim EJ. The influence of covert narcissism on social phobia- The mediating effects of social self-efficacy. Korean Journal of Psychology. 2009;28(3):627-642.

19. Kang HA, Kim A. Development and validation of a social self-efficacy scale for college students. Korean Journal of Educational Psychology. 2013;27(2):263-283.

20. Park HJ, Jang IS. Stress, depression, coping styles and satisfaction of clinical practice in nursing students. The Journal of Korean Academic Society of Nursing Education. 2010;16(1):14-23.

21. Kim KE, Lee BY. The relationship between satisfaction with clinical practice and clinical performance ability for nursing students. The Journal of the Korea Contents Association. 2014;14(10):885-896. https://doi.org/10.5392/JKCA.2014.14.10.885

22. Whang SJ. The relationship between clinical stress, self-efficacy, and self-esteem of nursing college students. The Journal of Korean Academic Society of Nursing Education. 2006;12(2):205-213.

23. Lee M, Ahn Y, Cho I, Sohn M. Effectiveness of simulation integrated with problem based learning on clinical competency and selfefficacy in nursing students. Child Health Nursing Research. 2014; 20(2):123-131. https://doi.org/10.4094/chnr.2014.20.2.123

24. Kim JY, An MS, Park HJ. Effectiveness of infant care competence according to pediatric nursing practice at school. Korean ParentChild Health Journal. 2012;15(1):14-19.

25. Han JJ. Satisfaction of clinical practice and self-efficacy of clinical practice in nursing students [master's thesis]. Seoul: Ewha Womans University; 2012. p. 1-58.

26. Kim SO, Kang BH. The influence of nursing students' learning experience, recognition of importance and learning self-efficacy for core fundamental nursing skills on their self-confidence. Journal of the Korea Academia-Industrial cooperation Society. 2016;17(8): 172-182. https://doi.org/10.5762/KAIS.2016.17.8.172

27. Park YM, Ju HJ. Personality types of nurses and the relation between self-efficacy and clinical performance ability. Journal of Digital Convergence. 2016;14(11):333-345. https://doi.org/10.14400/JDC.2016.14.11.333 